\title{
Blue rubber-bleb naevus syndrome: report of a case with consumption coagulopathy complicated by manifest thrombosis
}

\author{
W.J.D.Hofhuis ${ }^{1}$, A.P. Oranje ${ }^{2}$, J.Bouquet ${ }^{3}$, and M.Sinaasappel ${ }^{3}$ \\ Departments of ${ }^{1}$ Paediatrics, Division of Haematology-Oncology, ${ }^{2}$ Dermatology and Venereology, Division of Paediatric Dermatology, \\ ${ }^{3}$ Paediatrics, Division of Gastro-enterology, Erasmus University and University Hospital Rotterdam/Sophia Children's Hospital, \\ Gordelweg 160, 3038 GE Rotterdam, The Netherlands
}

Received January 12, 1988 / Accepted October 5, 1989

\begin{abstract}
Blue rubber-bleb naevus (BRBN) syndrome is a rare disorder characterized by subcutaneous and gastrointestinal haemangiomas. The latter may lead to bleeding complications. A case is reported in which a process of chronic intravascular coagulation resulted in serious thrombotic complications. In the presence of a chronic consumption coagulopathy, it remains uncertain whether antiplatelet drugs are of prophylactic antithrombotic value.
\end{abstract}

Key words: Blue rubber-bleb naevus - Consumption coagulopathy - Thrombosis - Aspirin

\section{Introduction}

In 1958 Bean [2] described a syndrome consisting of haemangiomatous malformations located in the skin and gastro-intestinal tract and named it Blue rubber-bleb naevus syndrome (BRBN) as the cavernous haemangiomas look like rubber nipples. Most cases are sporadic, although an autosomal dominant pattern of inheritance has been suggested [5]. BRBN syndrome in most cases is present from birth or early childhood and may be complicated by gastro-intestinal bleeding and orthopaedic abnormalities. According to strict criteria only 21 cases in the paediatric age group have so far been reported. Treatment of BRBN syndrome and its various complications is mainly symptomatic [8].

\section{Case report}

An 1.5-year-old girl was admitted to the Sophia Children's Hospital in March 1979 for investigation of multiple blue painless swel-

Offprint requests to: W.J.D. Hofhuis

Abbreviation: $\mathrm{BRBN}=$ Blue rubber-bleb naevus syndrome lings distributed over the body. Though present since birth, rapid growth of the lesions had been observed during several months before admission. There was also a history of chronic pallor. The parents were not consanguinous and there were no family members known to have the same disorder.

On physical examination the skin was pale with no bruising. Many bluish subcutaneous nodules were noted, located on the right half of the chest, the extremities (Fig.1) and the vulva. On palpation the consistency of these haemangiomas was soft and rubber-like.

Investigations to document the presence of non-cutaneous haemangiomas were undertaken. X-ray series of the upper and lower gastro-intestinal tract showed no abnormalities after bariumcontrast intake. Superior mesenteric arteriography revealed a $5 \mathrm{~cm}$ area at the ileo-coecal region compatible with haemangiomatosis.

On colonoscopy a vascular bleb was seen on the sigmoidorectal border and two similar lesions in the distal part of the descendent colon. Laboratory investigations (Table 1) on admission in 1979 indicated the presence of a consumption coagulopathy. The presence of a microangiopathic haemolytic anaemia was indicated by a low haptoglobin, a mildly increased reticulocyte count and in particular by the presence of schistocytes. At the same time a mild

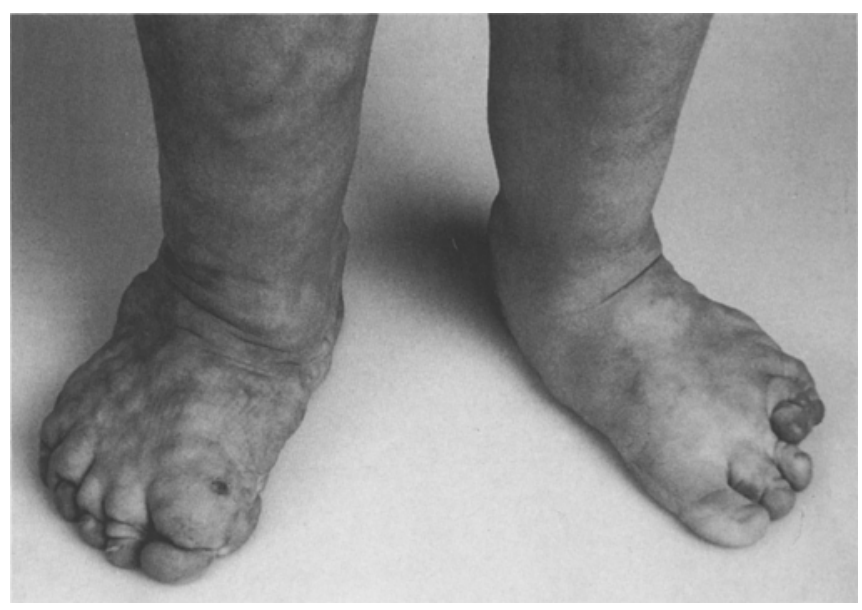

Fig. 1. Blue rubber-bleb naevus lesions on the feet with secondary phlebectasias 
Table 1. Laboratory results. A: initially; B: during manifest thrombosis; C: during antiplatelet therapy; D: off antiplatelet therapy

\begin{tabular}{|c|c|c|c|c|}
\hline & $\begin{array}{l}\text { A } \\
(1979)\end{array}$ & $\begin{array}{l}\text { B } \\
(1985)\end{array}$ & $\begin{array}{l}C \\
(1986)\end{array}$ & $\begin{array}{l}\text { D } \\
(1987)\end{array}$ \\
\hline $\mathrm{Hb}(\mathrm{g} / \mathrm{dl})$ & 6.4 & 9.6 & 10.4 & 10.8 \\
\hline $\mathrm{Ht}(\%)$ & 23 & 34 & 32 & 33 \\
\hline $\begin{array}{l}\text { Erythrocyte } \\
\text { count } / \mu l\end{array}$ & 3.6 & 4.0 & 3.6 & 3.5 \\
\hline Reticulocytes (\%o) & 32 & 35 & 26 & 26 \\
\hline Haptoglobin ( $g / 1)$ & $<0.38$ & $<0.38$ & $<0.38$ & $<0.38$ \\
\hline Schistocytes & Present & Present & Present & Present \\
\hline $\begin{array}{l}\text { Thrombocyte count } \\
\left(\times 10^{9} / 1\right)\end{array}$ & 250 & 90 & 134 & 120 \\
\hline APTT $(28-33 \mathrm{sec})$ & 31 & 30 & 28 & 26 \\
\hline $\begin{array}{l}\text { Fibrinogen (Clauss) } \\
(\mathrm{g} / \mathrm{l})\end{array}$ & 0.8 & 0.7 & 1.2 & 0.9 \\
\hline $\begin{array}{l}\text { Fibrin(ogen) } \\
\text { degradation } \\
\text { products (latex) } \\
(\mu \mathrm{g} / \mathrm{ml})\end{array}$ & $30-40$ & $80-100$ & $80-100$ & $100-120$ \\
\hline Fibrin monomers & Not done & Present & Present & Present \\
\hline Stage & Initial & $\begin{array}{l}\text { Throm- } \\
\text { bosis }\end{array}$ & Therapy & $\begin{array}{l}\text { After } \\
\text { therapy }\end{array}$ \\
\hline
\end{tabular}

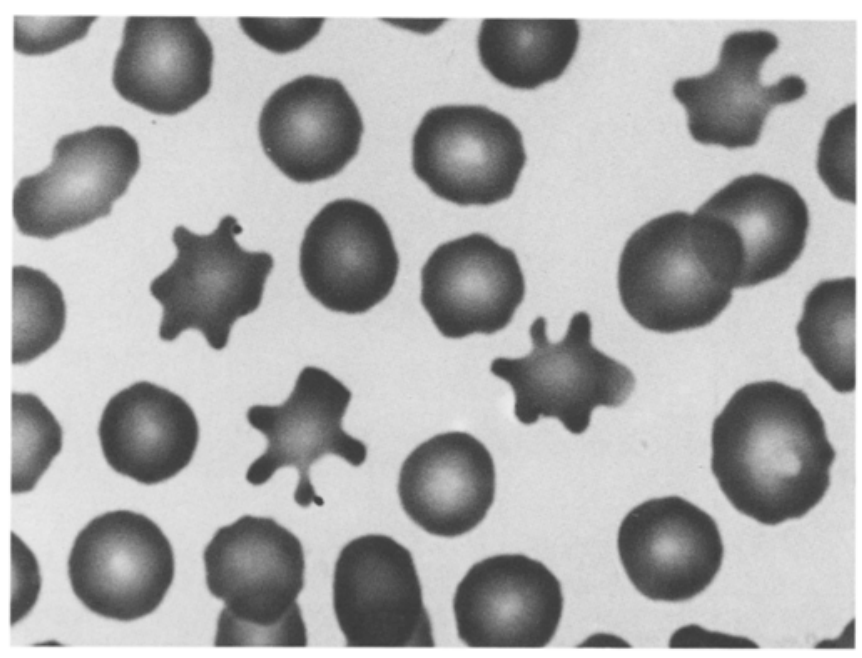

Fig. 2. Blood smear: note the "jig-saw puzzle" variant of schistocytes as a result of microangiopathic haemolytic anaemia

iron deficiency was found and positive results were obtained for faecal occult blood loss.

A conservative therapeutic approach was initially applied. Oral iron therapy was prescibed. Compression bandages of the legs were tried, but without success. The patient then discontinued her visits to the out-patient department. Five years later she returned, by which time the skin lesions had become more extensive.

Laboratory evaluation again showed the presence of a chronic consumption coagulopathy with micro-angiopathic haemolytic anaemia (Table 1 and Fig. 2).

The patient was now no longer iron deficient and repeated analyses revealed no occult gastro-intestinal blood loss.

In the spring of 1985 she was admitted in a critically ill condition with a temperature of $40^{\circ} \mathrm{C}$. Intraveneous antibiotics were started (first gentamicin and cefamandole, later penicillin $\mathrm{G}, 6 \times$ 1250000 intravenously). Pneumococci were isolated from blood cultures. During this period a painful swelling of the right leg developed and an evident clinical diagnosis of deep venous (ileofemoral) thrombosis was made, which was confirmed by ultrasound investigations. As a result of this complication she became unable to walk and extensive revalidation therapy had to be instituted.

Prophylactic antithrombotic therapy with low dose aspirin ( $3 \mathrm{mg} / \mathrm{kg}$ per day) and dipyramidole ( $4 \mathrm{mg} / \mathrm{kg}$ per day) was started and continued for a period of 12 months. Revalidation therapy was succesful and very careful monitoring did not reveal any gastro-intestinal bleeding during the observation period.

Though no dramatic changes in the haemostatic profile were observed, thrombocyte counts remained above $100 \times 10^{9} / 1$ and fibrinogen levels remained above $1.0 \mathrm{~g} / 1$ during the period of antiplatelet therapy.

\section{Discussion}

Haemostatic abnormalities have not been previously reported in BRBN-syndrome, except for thrombocytopaenia in the case of Fretzin and Potter [4]. In our patient the presence of a consumption coagulopathy is documented. In localised giant haemangiomas this is known as Kasabach-Merritt syndrome [6]. In this syndrome trapping of platelets and their subsequent activation results in a process of localized intravascular coagulation with consumption of clotting factors [7,9]. Consumption coagulopathy causes an instability of the thrombohaemorrhagic balance. This may lead to acute bleeding complications, but - in contrast - may also predispose to thrombotic complications. Our patient presented with manifest thrombosis during a period of severe infection and prolonged immobilisation, so called "thrombogenic circumstances".

Active treatment of a consumption coagulopathy becomes necessary in the presence of either bleeding or thrombosis. However, in this case of BRBN syndrome consumption coagulopathy can neither be treated by complete removal or eradication of the vascular malformations nor by generating local thrombosis [10] in the widespread haemangiomas. Various drugs have been reported to improve the coagulopathy in Kasabach-Merritt syndrome, including heparin [3] and corticosteroids [1]. Long-term therapy with aspirin and dipyramidole was reported by Koerper et al. [7]. This treatment resulted in an improvement in platelet count and clotting factor abnormalities and prevented clinical bleeding problems. By a stabilising effect on the haemostatic equilibrium this therapy may diminish the risk of both haemorrhagic and thrombotic derangements.

This report illustrates that the presence of a chronic consumption coagulopathy in BRBN syndrome may lead to manifest thrombotic complications, either by its nature or precipitated by so called "thrombogenic circumstances", i.c. pneumococcal septicaemia and immobilisation.

The possible prophylactic antithrombotic value of long-term therapy with low dose aspirin and dipyramidole in these circumstances remains uncertain. 


\section{References}

1. Bartoshesky LE, Bull M, Feingold M (1978) Corticosteroid treatment of cutaneous hemangiomas: how effective?: a report on 24 children. Clin Pediatr 17:625-638

2. Bean WB (1958) Vasular spiders and related lesions of the skin. Thomas, Springfield, pp 178-185

3. Carnelli V, Bellini F, Ferrari M, Rossi E, Masera G (1977) Giant hemangioma with consumption coagulopathy: sustained reponse to heparin and radiotherapy. J Pediatr 91:504-505

4. Fretzin DF, Potter B (1965) Blue rubber-bleb nevus. Arch Intern Med 116:924-929

5. Gilardi S, Harms M (1982) Genetische Aspekte des Blue Rubber Bleb Nävussyndroms und der multiplen gegeneralisierten Glomangiomatose. Hautarzt 33:96-100
6. Kasabach HH, Merritt KK (1940) Capillary hemangioma with extensive purpura: report of a case. Am J Dis Child 59:10631070

7. Koerper MA, Addiego JE, Lorimier AA de, Lipow H, Price $\mathrm{D}$, Lubin $\mathrm{BH}$ (1983) Use of aspirin and dipyramidole in children with platelet trapping syndromes. J Pediatr 102:311-314

8. Oranje AP (1986) Blue Rubber Bleb Nevus Syndrome. Pediatr Dermatol 3:304-310

9. Sondel PM, Ritter MW, Wilson DG, Lieberman LM (1984) Use of ${ }^{111}$ In platelet scans in the detection and treatment of Kasabach-Merritt syndrome. J Pediatr 104:87-89

10. Warrell RP, Kempin SJ (1985) Treatment of severe coagulopathy in the Kasabach-Merritt syndrome with aminocaproic acid and cryoprecipitate. N Eng1 J Med 313:309-312

\section{Osler's Personal Ideals}

I have had three personal ideals. One, to do the day's work well and not to bother about tomorrow. The second ideal has been to act the Golden Rule, as far as in me lay, toward my professional brethren and towards the patients committed to my care. And the third has been to cultivate such a measure of equanimity as would enable me to bear success with humility, the affection of my friends without pride, and to be ready when the day of sorrow and grief come to meet it with courage befitting a man.

Osler, in his Speech in May, 1905, at the Farewell Dinner of the Medical profession of America and Canada, when he was bound for Oxford 